\title{
Clinical, hormonal and genetic characteristics of androgen insensitivity syndrome in 39 Chinese patients
}

\author{
Qingxu Liu, Xiaoqin Yin and Pin Li
}

\begin{abstract}
Background: Abnormal androgen receptor (AR) genes can cause androgen insensitivity syndrome (AIS), and AIS can be classified into complete androgen insensitivity syndrome (CAIS), partial androgen insensitivity syndrome (PAIS) and mild AIS. We investigated the characteristics of clinical manifestations, serum sex hormone levels and AR gene mutations of 39 AlS patients, which provided deeper insight into this disease.

Methods: We prospectively evaluated 39 patients with 46, XY disorders of sex development (46, XY DSD) who were diagnosed with AlS at the Department of Endocrinology of Shanghai Children's Hospital from 2014 to 2019. We analysed clinical data from the patients including hormone levels and AR gene sequences. Furthermore, we screened the AR gene sequences of the 39 AIS patients to identify probable mutations.

Results: The 39 AIS patients came from 37 different families; 19 of the patients presented CAIS, and 20 of them presented PAIS. The CAIS patients exhibited a higher cryptorchidism rate than the PAIS (100 and 55\%, $P=0.001$ ). There were no significant difference between the CAIS and PAIS groups regarding the levels of inhibin B (INHB), sex hormone-binding globulin (SHBG), basal luteinizing hormone (LH), testosterone $(\mathrm{T})$, or basal dihydrotestosterone (DHT), the T:DHT ratio, DHT levels after human chorionic gonadotropin (HCG) stimulation or T levels after HCG stimulation. However, the hormone levels of AMH $(P=0.010)$, peak LH $(P=0.033)$, basal FSH $(P=0.009)$ and peak FSH $(P=0.033)$ showed significant differences between the CAIS group and the PAIS group. Twenty-one reported pathogenic and 9 novel AR mutations were identified. Spontaneous AR mutations were found in 5 AIS patients, and 21 patients inherited mutations from their mothers, who carried heterozygous mutations.

Conclusions: Forty-six XY DSD patients with cryptorchidism and female phenotypes were highly suspected of having AIS. We demonstrated that CAIS patients could not be distinguished by their hormone levels alone. Compared with PAIS patients, CAIS patients exhibited higher basal FSH, peak FSH, and peak LH hormone levels but lower AMH expression. We identified 21 reported pathogenic AR mutations and 9 novel AR mutations that led to different types of AIS. Missense mutations were the major cause of AIS and mostly occurred in exon 7 of the AR gene. These findings provided deeper insight into the diagnosis and classification of AIS and will even contributed to its clinical assessment.
\end{abstract}

Keywords: Androgen insensitivity syndrome (AIS), Androgen receptor mutation, 46, XY DSD, Mutation

\footnotetext{
*Correspondence: lipin2019@126.com

Department of Endocrinology, Shanghai Children's Hospital, Children's Hospital Affiliated to Shanghai Jiao Tong University, Shanghai 200062,

People's Republic of China
}

(c) The Author(s). 2020 Open Access This article is licensed under a Creative Commons Attribution 4.0 International License, which permits use, sharing, adaptation, distribution and reproduction in any medium or format, as long as you give appropriate credit to the original author(s) and the source, provide a link to the Creative Commons licence, and indicate if changes were made. The images or other third party material in this article are included in the article's Creative Commons. licence, unless indicated otherwise in a credit line to the material. If material is not included in the article's Creative Commons licence and your intended use is not permitted by statutory regulation or exceeds the permitted use, you will need to obtain permission directly from the copyright holder. To view a copy of this licence, visit http://creativecommons.org/licenses/by/4.0/. The Creative Commons Public Domain Dedication waiver (http://creativecommons.org/publicdomain/zero/1.0/) applies to the data made available in this article, unless otherwise stated in a credit line to the data. 


\section{Background}

Androgen insensitivity syndrome (AIS) is an X-linked genetic disease that is commonly caused by $46, \mathrm{XY}$ disorders of sex development (46, XY DSD) [1]. The human androgen receptor (AR) gene is located in the Xq11-12 region and exhibits 8 exons that encode a peptide of 920 aa in length [2]. There are three ligand-dependent transcription factors corresponding to the major functional regions of the AR gene. These regions can be activated by androgens and interact with other proteins [3]. The critical period of reproductive organ development is from 8 to 14 weeks of gestation in humans depending on the presence of androgens and a normal AR. Therefore, abnormal androgen secretion and a defective AR can affect the conversion of androgens. Common receptor defects in AIS patients result from mutations in AR genes. Most reports of AR mutations have focused on small families and have lacked hormonal analysis [4], while some reports addressing the clinical and hormonal characteristics of large groups do not reveal the underlying mutations. We retrospectively studied the clinical manifestations, genotypes and serum hormones of 39 AIS patients in whom AR gene mutations were identified to lay a foundation for better understanding AIS.

\section{Subjects and methods Subjects}

Informed parental consent, patient consent and approval from the Hospital Ethics Committee were obtained before initiating the study. Thirty-nine patients with AIS, including 4 subjects from 2 families, were recruited for this study from the Department of Endocrinology, Shanghai Children's Hospital, from 2014 to 2019. Thirty-eight of the patients were diagnosed with AIS under the age of 11 , and 1 patient was diagnosed at the age of 13 years and 8 months. The patients met the following criteria for AIS: they exhibited a 46, XY karyotype, SRY (+), normal adrenal function, AR mutations and serum hormone levels consistent with AIS. We investigated the clinical manifestations, family history, related sex hormones and AR gene sequences of the patients. In our study, AIS was classified as either complete androgen insensitivity syndrome (CAIS) or partial androgen insensitivity syndrome (PAIS) according to the clinical manifestations.

\section{External genital phenotype evaluation}

We evaluated external genital phenotypes according to the PRADER classification [5]. Phallus length was compared with the data from normal Chinese children. The phallus was placed in an extended state, and the length from the pubic symphysis to the top of the glans along the dorsal side of the phallus excluding the length of the foreskin was recorded as the length of the phallus.
Cryptorchidism was confirmed by physical examination and ultrasound examination in line with the diagnostic criteria for paediatric cryptorchidism. Cryptorchidism was classified as intra-abdominal cryptorchidism or inguinal cryptorchidism according to the location of the testis.

\section{Hormonal analysis}

To evaluate testicular function, all patients underwent gonadotropin-releasing hormone $(\mathrm{GnRH})$ stimulation to assess hypothalamic-pituitary-gonadal (HPG) axis function and human chorionic gonadotropin (HCG) stimulation. Sex hormones including anti-Mullerian hormone (AMH), inhibin B (INHB), oestradiol (E2), sex hormone binding globulin (SHBG), basal testosterone (T), basal dihydrotestosterone (DHT), basal luteinizing hormone $(\mathrm{LH})$, peak $\mathrm{LH}$, basal follicle-stimulating hormone $(\mathrm{FSH})$, peak FSH, DHT after human chorionic gonadotropin (HCG) stimulation and T after HCG stimulation were detected. Serum LH and FSH concentrations were tested with $\mathrm{LH}$ and FSH detection kits (Beckman Coulter) and measured with an automatic immunoluminescence analyser (UnicelDxI 800). Serum AMH and INHB were detected in solid-phase sandwich enzyme-linked immunosorbent assays (ELISAs) purchased from Guangzhou Kangrun Biotechnology Co., Ltd. E2, T and DHT were tested by ELISA and measured with a USA Polar ELx800 microplate reader.

\section{AR gene analysis}

Genomic DNA was obtained from peripheral blood leukocytes via a salting out procedure [6]. Exons 1-8 of the AR gene were amplified, and Sanger sequencing was used to screen for mutations. We searched the mutation assessment database within the human gene mutation database (http://www.ncbi.nlm.nih.gov) and the androgen mutation database (http://androgendb.mcgill.ca). PolyPhen-2 software was applied to perform pathogenicity analysis of amino acid changes caused by mutations.

\section{Statistical analysis}

SPSS 25.0 software (manufactured by International Business Machines Corporation) was used to analyse these data. The nonparametric data were analysed with the Mann-Whitney $U$ test and are presented as median values. The normally distributed data were analysed with the $\mathrm{t}$-test and are presented as the mean \pm S.D. Spearman correlation analysis was used for correlation analysis. Fisher's test was applied to compare the incidence of cryptorchidism. A $P$-value $<0.05$ was considered to indicate a significant difference, which was indicated as follows; ${ }^{*} P<0.05,{ }^{* *} P<0.01$. 


\section{Results}

\section{Clinical manifestations}

The data analysis showed that 20 (51.28\%) patients exhibited a complete female external genital phenotype (PRADER grade 0) among the 39 patients with AIS, and 19 (48.72\%) patients presented phenotypes of PAIS (PRADER grades $1-5)$. Thirty patients (76.92\%) exhibited cryptorchidism, among which 24 patients exhibited inguinal cryptorchidism, and 6 patients exhibited intraabdominal cryptorchidism. Only one patient presented intra-abdominal cryptorchidism in the PAIS group. The CAIS group displayed an apparent correlation with cryptorchidism. All PAIS patients exhibited a microphallus phenotype, and 9 of them exhibited hypospadias. The most prominent clinical manifestation of 39 AIS patients was cryptorchidism, and the number of cryptorchidism cases among the CAIS patients was greater than that among PAIS patients $(P<0.01)$ (Table 1$)$. However, there was no significant difference in the incidence of intra-abdominal cryptorchidism between the two groups (Table 2).

\section{Hormones}

We compared the hormone levels of prepubescent patients under the age of 11 in Tanner stage I, in addition to case C14, in Tanner stage III. Twenty-five of the 39 AIS patients underwent AMH and INHB measurement, which was not performed in the other 14 patients at their own request. The correlation analysis of serum sex hormone levels in AIS patients showed that AMH was positively correlated with INHB $(r=0.463)$ and T after HCG stimulation $(r=0.505, P<0.01)$. INHB was positively correlated with T after HCG stimulation $(r=0.618, P<0.01)$ (Fig. 1$)$. Basal LH was positively correlated with peak LH $(r=$ $0.495, P<0.01)$, basal testosterone $(r=0.530, P<0.01)$ and DHT after HCG stimulation $(r=0.488, P<0.01)$. There was a close positive correlation between basal FSH and peak FSH ( $r=0.902, P<0.01)$ (Fig. 2).

There was no significant difference between the CAIS and PAIS groups regarding the hormone levels of INHB, SHBG, basal LH or basal DHT, the T:DHT ratio, DHT after HCG stimulation or T after HCG stimulation. The hormone levels of AMH $(P=0.010)$, peak LH $(P=0.033)$, basal FSH $(P=0.009)$ and peak FSH $(P=0.033)$ showed statistically significant differences between the CAIS and PAIS groups. The data

Table 1 Incidence of cryptorchidism in patients with AIS $(P=0.001)$

\begin{tabular}{llllr}
\hline AIS & Non-cryptorchidism & Cryptorchidism & Total cryptorchidism & Ratio \\
\hline CAIS & 0 & 19 & 19 & $100 \%$ \\
PAIS 9 & 11 & 20 & $55 \%$ \\
Total & 9 & 30 & 39 & \\
\hline
\end{tabular}

Table 2 Incidence of inguinal cryptorchidism in patients with AIS $(P=0.372)$

\begin{tabular}{lllll}
\hline AIS & $\begin{array}{l}\text { Inguinal } \\
\text { cryptorchidism }\end{array}$ & $\begin{array}{l}\text { Intra-abdominal } \\
\text { cryptorchidism }\end{array}$ & $\begin{array}{l}\text { Total } \\
\text { cryptorchidism }\end{array}$ & Ratio \\
\hline CAIS & 14 & 5 & 19 & $73.68 \%$ \\
PAIS & 10 & 1 & 11 & $90.9 \%$ \\
Total & 23 & 6 & 30 & \\
\hline
\end{tabular}

suggested that CAIS patients presented higher levels of basal FSH, peak FSH, peak LH and lower AMH than PAIS patients (Table 3 and Fig. 3).

\section{Molecular studies}

Data analysis showed that 21 patients inherited heterozygous AR mutations from their mothers, and the other 5 patients exhibited spontaneous mutations. Most AR gene mutations identified in this study occurred in a ligand-binding domain (LBD) within an exon, and only one patient presented an intron mutation. As shown in Table 4, we found that 29 patients exhibited 21 types of reported pathogenic mutations, and the other 10 patients presented 9 novel AR gene mutations.

\section{Discussion}

\section{Clinical characteristics}

$\mathrm{T}$ and DHT are important androgens in the human body that act by binding to androgen receptors throughout an individual's lifespan [7]. Androgen insensitivity results in a series of abnormal characteristics of sexual development. Although the effect of AMH is normal in AIS patients and they do not have female internal genitalia, such as a uterus or ovaries, T and DHT cannot effectively promote the development of the Wolffian ducts or genitourinary sinus [8]. These patients may exhibit sexual dysplasia, blind vagina, cryptorchidism, microphallus or hypospadias [9]. Cryptorchidism was the major phenotype observed in this study, which was characterized as inguinal cryptorchidism in most cases. Intraabdominal cryptorchidism showed a higher incidence in CAIS patients than in PAIS patients. Inguinal cryptorchidism was more common because androgens can drive testicular descent into the inguinal region. The external genitalia of the PAIS patients were ambiguous, and these patients exhibited microphallus with or without hypospadias [10]. However, hypospadias is not sufficient for the identification of AIS and other 46, XY DSDs. In 46, XY DSD patients with cryptorchidism and a female phenotype, after excluding complete gonadal dysplasia, $17 \alpha$-hydroxylase and $17 \beta$-HSD type 3 deficiency and interstitial cell dysplasia, it is necessary to perform the diagnosis of AIS. 


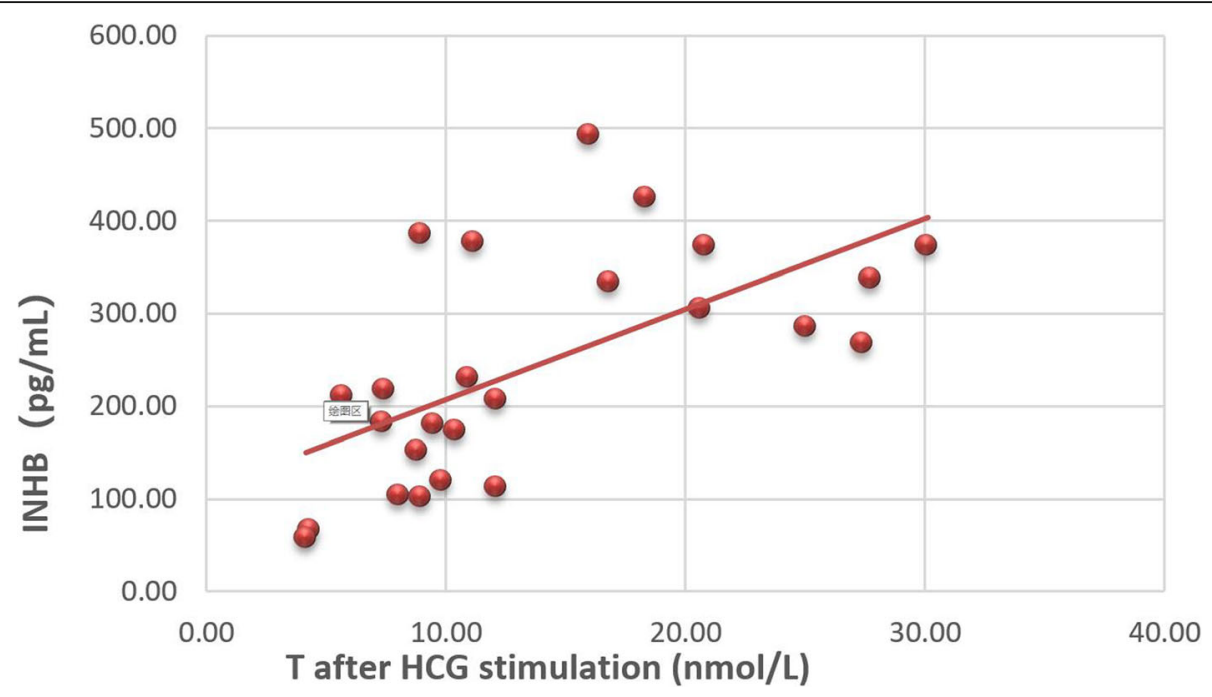

Fig. 1 Correlation analysis of INHB and T after HCG stimulation $(r=0.618, P<0.01)$

\section{Hormones}

According to basal hormone levels, prepubescent AIS patients might exhibit higher $\mathrm{T}$ or E2 levels. There was no significant difference in $\mathrm{T}$ or $\mathrm{E} 2$ levels between the PAIS group and the CAIS group. The basal T level may present a characteristic increment in AIS patients since most patients with 46, XY DSD are diagnosed with male dysfunction with a decrease in $\mathrm{T}$. According to previous studies, AIS patients exhibit higher E2 levels in adulthood [11]. This study suggested that AIS patients might present a nondetectable elevation of serum oestradiol in prepuberty. In addition, AIS patients may show breast development at puberty.
Consistent with previous studies, we found that the LH level increased dramatically after $\mathrm{GnRH}$ stimulation in AIS patients, indicating that a large amount of $\mathrm{LH}$ was stored in the anterior pituitary [12]. Our data demonstrated that CAIS patients presented higher levels of FSH and peak LH than PAIS patients. The peak LH levels of CAIS $(27.39 \pm 3.18 \mathrm{IU} / \mathrm{L})$ and PAIS $(18.86 \pm$ $2.25 \mathrm{IU} / \mathrm{L})$ patients showed an evident increase compared with those of healthy children, and their basal LH levels were approximately 23 times or 17 times higher than those in healthy children. However, peak FSH levels exhibited a weak response to GnRH stimulation, reaching levels approximately 3 times higher than the basal

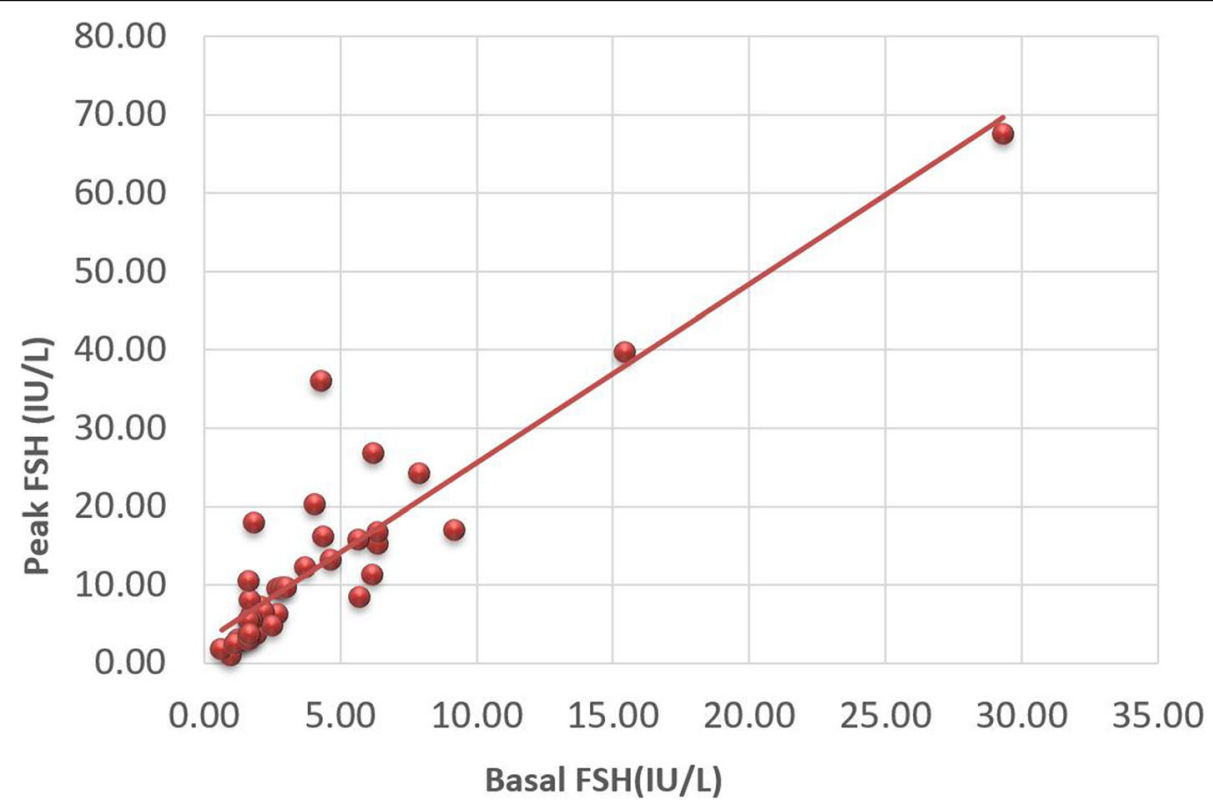

Fig. 2 Correlation analysis of basal FSH and peak FSH $(r=0.902, P<0.01)$ 
Table 3 Hormone levels and statistical differences in patients with AIS

\begin{tabular}{|c|c|c|c|c|c|}
\hline Hormones & Group & Median or $\overline{\mathbf{X}} \pm \mathrm{SD}(\mathrm{nmol} / \mathrm{L})$ & Range & $\mathrm{N}$ & $\boldsymbol{P}$ value \\
\hline \multirow[t]{2}{*}{$\mathrm{AMH}(\mathrm{ng} / \mathrm{mL})$} & CAIS & 32.60 & $(19.02-146.38)$ & 9 & 0.010 \\
\hline & PAIS & 154.71 & $(14.77-755.80)$ & 16 & \\
\hline \multirow[t]{2}{*}{ Oestradiol (pmol/L) } & CAIS & 73 & $(73.00-110.00)$ & 18 & 0.303 \\
\hline & PAIS & 73 & $(73.00-202.00)$ & 20 & \\
\hline \multirow[t]{2}{*}{ Basal LH (IU/L) } & CAIS & 1.18 & $(0.36-4.93)$ & 18 & 0.762 \\
\hline & PAIS & 1.085 & $(0.20-5.11)$ & 20 & \\
\hline \multirow[t]{2}{*}{ Basal T (nmol/L) } & CAIS & 1.105 & $(0.35-4.80)$ & 18 & 0.303 \\
\hline & PAIS & 0.46 & $(0.35-8.96)$ & 20 & \\
\hline \multirow[t]{2}{*}{ T after HCG stimulation (nmol/L) } & CAIS & 10.61 & $(5.65-20.82)$ & 18 & 0.072 \\
\hline & PAIS & 16.4 & $(4.15-54.00)$ & 20 & \\
\hline \multirow[t]{2}{*}{ Basal DHT (pg/ml) } & CAIS & 70.69 & $(12.16-514.34)$ & 18 & 0.331 \\
\hline & PAIS & 45.4 & $(12.16-980.23)$ & 20 & \\
\hline \multirow[t]{2}{*}{ DHT after HCG stimulation (pg/ml) } & CAIS & 255.8 & $(42.00-491.42)$ & 18 & 0.762 \\
\hline & PAIS & 234.13 & $(80.57-1006.37)$ & 20 & \\
\hline \multirow[t]{2}{*}{ Basal FSH (IU/L) } & CAIS & 4.05 & $(1.29-29.32)$ & 18 & 0.009 \\
\hline & PAIS & 1.735 & $(0.65-6.26)$ & 20 & \\
\hline \multirow[t]{2}{*}{ Peak FSH (IU/L) } & CAIS & 13.65 & $(3.03-67.54)$ & 18 & 0.033 \\
\hline & PAIS & 5.45 & $(0.99-35.99)$ & 20 & \\
\hline \multirow[t]{2}{*}{$\mathrm{T}: \mathrm{DHT}$ ratio } & CAIS & 8.04 & $(3.67-34.42)$ & 18 & 0.228 \\
\hline & PAIS & 13.815 & $(2.74-26.75)$ & 20 & \\
\hline \multirow[t]{2}{*}{ INHB (pg/mL) } & CAIS & $263.06 \pm 33.62$ & $(172.94-424.66)$ & 9 & 0.548 \\
\hline & PAIS & $231.88 \pm 33.26$ & $(57.48-493.50)$ & 16 & \\
\hline \multirow[t]{2}{*}{ Peak LH (IU/L) } & CAIS & $27.39 \pm 3.18$ & $(8.51-50.29)$ & 18 & 0.033 \\
\hline & PAIS & $18.86 \pm 2.25$ & $(1.02-35.19)$ & 20 & \\
\hline \multirow[t]{2}{*}{ SHBG $(\mathrm{nmol} / \mathrm{l})$} & CAIS & $122.46 \pm 10.82$ & $(22.70-195.70)$ & 18 & 0.348 \\
\hline & PAIS & $108.89 \pm 9.39$ & $(35.20-177.70)$ & 20 & 0.010 \\
\hline
\end{tabular}

(the Mann-Whitney test results are expressed as median values, and the $t$ test results are expressed as the mean and standard deviations, significant differences were considered at $P<0.05$ )

FSH level. These data suggested that peak LH levels in AIS patients show a higher correlation with androgen resistance and influence the severity of AIS in prepubescent children.

It is worth noting that the T level after HCG stimulation was lower in CAIS patients than in PAIS patients, while the DHT level after HCG stimulation was higher than that in PAIS patients. We suspected that $\mathrm{T}$ might be converted into more bioactive DHT by the $5 \alpha$ reductase 2 enzyme in the CAIS group, which showed stronger androgen resistance to counter-receptor defects. In male infants with CAIS within the few months after birth, $\mathrm{T}$ levels do not increase after HCG stimulation, whereas the $\mathrm{T}$ levels of male infants with PAIS present a spontaneous increase, which could indirectly support the findings our study [13].

$\mathrm{AMH}$ and INHB are biomarkers of the testis that are secreted by Sertoli cells which are activated in infancy and childhood [14]. AMH and INHB play important roles in gonadal development and sex differentiation and have discriminating effects on patients with impalpable testis [15-17]. The data showed no significant difference in INHB levels between the two groups distinguished in this study, while there was a significant difference in AMH levels $(P=0.010)$. CAIS patients exhibited lower concentrations of AMH than PAIS patients, suggesting that AMH is crucial for the classification of AIS. Compared with the reference range reported in the literature [18], the median hormone level of AMH within the CAIS patients was within the normal range, while the median hormone level of AMH within the PAIS patients was above the normal range. These results may be due to the combined regulation of FSH and androgen.

The PAIS patients presented higher T:DHT ratios and SHBG concentrations than the CAIS group, but these differences were not significant. The T:DHT ratios of case $\mathrm{C} 8$ and case $\mathrm{C} 16$ were above 30 , although we did not find any mutations in these patients via SRD5A2 

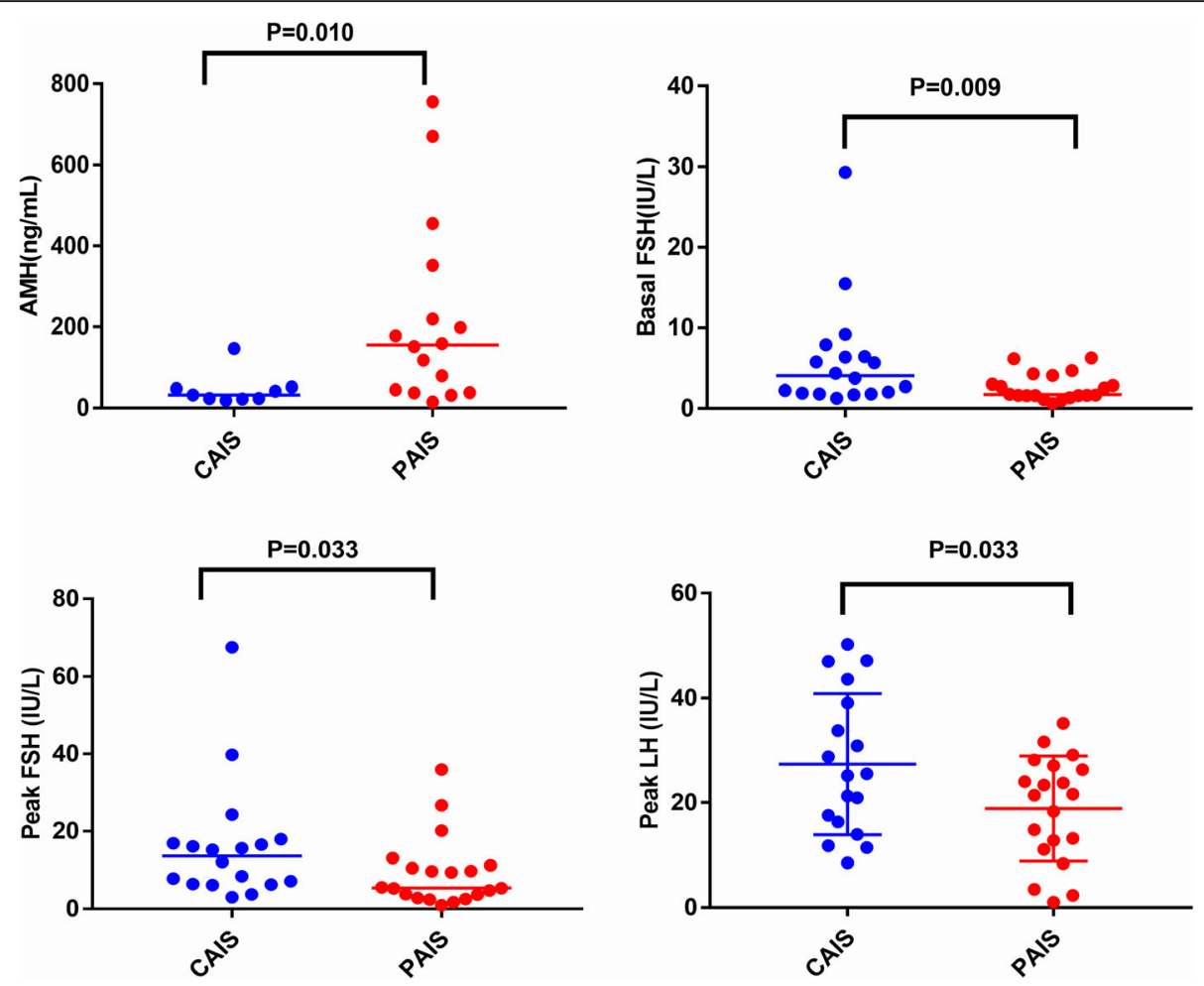

Fig. 3 Hormones showing significant differences in the two types of AIS patients

gene sequencing. These results suggested that the $\mathrm{T}$ : DHT ratio cannot be used alone to differentiate AIS from other 46, XY DSDs. The T:DHT ratio in most AIS patients was lower than in typical cases of SRD5A2 deficiency [19]. In addition, this ratio may be higher than 30 a small number of AIS patients. The serological manifestations of prepubescent AIS patients were somewhat similar to those in early adolescence or puberty. An increase in $\mathrm{LH}$ secretion contributes to $\mathrm{T}$ secretion, and $\mathrm{T}$ can be converted into DHT by the SRD5A2 enzyme or into oestradiol by the aromatase enzyme.

\section{Genetic analysis}

Mutations in the AR gene can lead to AIS, and AIS requires genetic diagnosis with or without a family history of AIS because the rate of spontaneous mutation is $30 \%$ [20]. Common mutations of the AR gene include missense mutations, insertions and deletions. Most of these mutations are relevant to AIS, and few are related to gonadal tumours. Consistent with international research findings, the most common mutations identified in this study were missense mutations, and exon 7 was the exon that was most prone to mutation. The majority of patients exhibited AR gene missense mutations, including 1 mutation that led to the termination of protein synthesis. Other kinds of mutations caused different phenotypes, including transcriptional shear, frame shift mutations and gene duplications.

Cases C1 and C2, carrying the c.2107 T > C (p. Ser703Pro) mutation, came from the same family. Their mutations were inherited from their mother and exhibited pathogenic potential according to PolyPhen-2 analysis. This mutation was not reported previously. However, there were some similar reports in the McGill mutation database; for example, the c.2107 T > G (p. Ser703Ala) mutation of the AR gene causes a complete female phenotype [21]. c.2740C > G (p. Pro 914 Ala) was indicated to cause CAIS in this study, and this mutation has not been reported previously. Studies have indicated that similar amino acid changes, including the c.2740C > T (p. Pro914Ser) mutation, can cause PAIS, which was also found in case P20 in this study [20]. The previously reported c. $2450-42 \mathrm{G}>\mathrm{A}$ mutation creates an alternative splice acceptor site in intron 6 of the AR gene, which could lead to the production of a large number of abnormal mRNAs and a relatively small number of wild-type mRNAs, resulting in AR protein dysfunction [22].

Four patients, including 3 CAIS patients and 1 PAIS patient, presented the c.2522G > A (p. Arg841His) hot spot mutation in this study. This mutation results in a broad range of phenotypes from a completely female phenotype to male phenotypes with minor degrees of undervirilisation [23], and the majority of these cases are 
Table 4 AR gene mutations in 39 AIS patients

\begin{tabular}{|c|c|c|c|c|c|c|c|c|c|}
\hline AIS & Sex & Age (yr) & Testis position & Mutation & Novel & Exon & Amino Acid & PolyPhen-2 & Family history \\
\hline$\overline{C 1}$ & $\mathrm{~F}$ & 1.3 & inguinal region & c.2107 T >C & $Y$ & 4, LBD & p. Ser 703 Pro & 1.000 & Y \\
\hline$C 2$ & $\mathrm{~F}$ & 1.6 & abdomen & c. $2107 \mathrm{~T}>\mathrm{C}$ & Y & 4, LBD & p. Ser703 Pro & 1.000 & Y \\
\hline C3 & $\mathrm{F}$ & 0.4 & inguinal region & c. $2740 C>G$ & Y & 8, LBD & p. Pro 914 Ala & 0.609 & n.a \\
\hline C4 & $\mathrm{F}$ & 1.1 & inguinal region & c. $2351 A>G$ & Y & 6, LBD & p. Gln 784 Arg & 0.998 & n.a \\
\hline C5 & $\mathrm{F}$ & 2.6 & inguinal region & c.2024 T > A, & Y & 4, LBD & p.Leu675GIn & 0.999 & n.a \\
\hline C6 & $\mathrm{F}$ & 4.4 & inguinal region & c. $2522 \mathrm{G}>\mathrm{A}$ & N & 7, LBD & p.Arg841His & 1.000 & Y \\
\hline $\mathrm{C} 7$ & $\mathrm{~F}$ & 2.1 & abdomen & c. $1768+1 G>C$ & Y & Intron & Change the shearing mode & $U$ & N \\
\hline $\mathrm{C} 8$ & $\mathrm{~F}$ & 2.9 & inguinal region & c. $2567 G>A$ & N & 7, LBD & p. Arg $856 \mathrm{His}$ & 1.000 & n.a \\
\hline C9 & $\mathrm{F}$ & 2.3 & abdomen & c. $1684 \mathrm{~A}>\mathrm{T}$ & Y & $2, \mathrm{DBD}$ & p.lle562Phe & 0.999 & n.a \\
\hline $\mathrm{C} 10$ & $\mathrm{~F}$ & 1 & inguinal region & c. $2522 \mathrm{G}>\mathrm{A}$ & N & 7, LBD & p.Arg841His & 1.000 & Y \\
\hline $\mathrm{C} 11$ & $\mathrm{~F}$ & 3.8 & inguinal region & c. $2086 G>A$ & N & 4, LBD & p.Asp696Asn & 0.999 & N \\
\hline $\mathrm{C} 12$ & $\mathrm{~F}$ & 3.8 & inguinal region & $c .2324 G>A$ & $\mathrm{~N}$ & 6, LBD & p.Arg775His & 1.000 & N \\
\hline $\mathrm{C} 13$ & $\mathrm{~F}$ & 1.8 & inguinal region & c. $2645 \mathrm{~T}>\mathrm{C}$ & $\mathrm{N}$ & 8, LBD & p.Leu882Pro & 1.000 & Y \\
\hline C14 & $\mathrm{F}$ & 13.7 & abdomen & c. $2117 A>G$ & N & 4, LBD & p.Asn706Ser & 0.999 & Y \\
\hline C15 & $\mathrm{F}$ & 2.1 & inguinal region & c. $2522 \mathrm{G}>\mathrm{A}$ & $\mathrm{N}$ & 7, LBD & p.Arg841His & 1.000 & n.a \\
\hline $\mathrm{C} 16$ & $\mathrm{~F}$ & 1.2 & inguinal region & c. $2290 \mathrm{~T}>\mathrm{C}$ & N & 5, LBD & p.Tyr764His & 1.000 & Y \\
\hline $\mathrm{C} 17$ & $\mathrm{~F}$ & 2.8 & abdomen & c. $2678 \mathrm{C}>\mathrm{T}$ & N & 8, LBD & p.Pro893Leu & 1.000 & Y \\
\hline C18 & $\mathrm{F}$ & 10.8 & inguinal region & c. $1858 \mathrm{~T}>\mathrm{C}$ & $\mathrm{N}$ & $3, \mathrm{DBD}$ & p. Cys620Arg & 1.000 & Y \\
\hline C19 & $\mathrm{F}$ & 1.4 & inguinal region & c.1415_1416insCGGC & Y & 1, NTD & p. Gly 472 fs & $U$ & Y \\
\hline P1 & M & 6.8 & inguinal region & c. $2612 C>G$ & N & 8, LBD & p.Ala871Gly & 0.999 & n.a \\
\hline P2 & M & 1 & scrotum & c. $2521 C>T$ & N & 7, LBD & p.Arg841Cys, & 1.000 & n.a \\
\hline P3 & M & 1.5 & inguinal region & c.1063G > T & $\mathrm{N}$ & 1, NTD & p.Glu355Term & $U$ & Y \\
\hline P4 & M & 1.9 & scrotum & c. $2104 C>A$ & $\mathrm{~N}$ & 4, LBD & p.Leu702lle & 0.995 & Y \\
\hline P5 & M & 1.9 & scrotum & C. $.528 \mathrm{C}>\mathrm{A}$ & N & 1, NTD & p.Ser176Arg & 0.842 & n.a \\
\hline P6 & M & 1.1 & scrotum & c. $2612 C>T$ & N & 8, LBD & p.Ala871Val & 0.994 & Y \\
\hline P7 & M & 1.6 & scrotum & c. $2531 C>A$ & $\mathrm{~N}$ & 7, LBD & p.Ala844Glu & 0.989 & n.a \\
\hline P8 & M & 0.9 & scrotum & c. $2531 C>A$ & $\mathrm{~N}$ & 7, LBD & p.Ala844Glu & 0.989 & n.a \\
\hline P9 & M & 1 & scrotum & $c .2338 C>T$ & $\mathrm{~N}$ & 6, LBD & p.Arg780Trp & 1.000 & Y \\
\hline P10 & M & 9.7 & scrotum & $c .528 \mathrm{C}>\mathrm{A}$ & $\mathrm{N}$ & 1, NTD & p.Ser176Arg & 0.842 & n.a \\
\hline P11 & M & 1,4 & inguinal region & c. $2221 \mathrm{~T}>\mathrm{A}$ & Y & $5, \mathrm{LBD}$ & p.Ser741Thr & 0.555 & Y \\
\hline P12 & M & 2.4 & abdomen & c. $1705 \mathrm{G}>\mathrm{T}$ & $\mathrm{N}$ & 2, DBD & p.Gly569Trp & 1.000 & n.a \\
\hline P13 & M & 1 & inguinal region & c. $2567 \mathrm{G}>\mathrm{A}$ & $\mathrm{N}$ & 7, LBD & p. Arg $856 \mathrm{His}$ & 1.000 & n.a \\
\hline P14 & M & 1.8 & inguinal region & c. $2441 \mathrm{~T}>\mathrm{A}$ & Y & 6, LBD & p. Phe814Tyr & 0.999 & n.a \\
\hline P15 & M & 1.1 & scrotum & c. $2638 \mathrm{G}>\mathrm{T}$, & $\mathrm{N}$ & 8, LBD & p. Asp880 Tyr & 1.000 & Y \\
\hline P16 & $\mathrm{F}$ & 1.2 & inguinal region & c. $2450-42 \mathrm{G}>\mathrm{A}$ & Y & 7, LBD & $U$ & $U$ & Y \\
\hline P17 & $\mathrm{F}$ & 1.7 & scrotum & c. $2450-42 \mathrm{G}>\mathrm{A}$ & Y & 7, LBD & $U$ & $U$ & Y \\
\hline P18 & M & 6.7 & inguinal region & $1823 G>A$ & N & 3, DBD & p.Arg608Gln & 1.000 & Y \\
\hline P19 & M & 10.7 & inguinal region & c.170_172dup & $\mathrm{N}$ & 1, NTD & p.Leu57dup & $U$ & Y \\
\hline P20 & $\mathrm{F}$ & 1.3 & inguinal region & c. $2740 \mathrm{C}>\mathrm{T}$ & $\mathrm{N}$ & 8, LBD & p.Pro914Ser & 0.996 & Y \\
\hline
\end{tabular}

$F$ Female, $M$ Male, n.a. data not available, $P$ Positive, $N$ Negative or no, $Y$ Yes, $U$ Unknown, LBD Ligand-binding domain, NTD N-terminal domain, DBD DNA-binding domain

diagnosed as CAIS. There were no specific correlations between genotypes and phenotypes identified in the AIS patients. Identical AR mutations can lead to variable phenotypic expression because one mutation can produce different phenotypes and appear in different individuals within a family. Forty-five allelic variants that may result in different phenotypes are currently recorded in the McGill AR mutation database. There are 
no available qualitative data on penetrance at present. The variable phenotypic expression of particular mutations may be due to differences in affected individuals such as somatic cell embedding [24-26].

In this research, we identified 21 reported pathogenic AR gene mutations in 29 patients, and we detected 9 novel mutations, including c.2107 T $>\mathrm{C}$ (p. Ser703Pro), c. $2740 \mathrm{C}>\mathrm{G}$, c. $2351 \mathrm{~A}>\mathrm{G}$ (p. Gln784Arg), c.2024 T > A (p. Leu675Gln), c.1684A > T (p. Ile562Phe), c.2221 T > A (p. Ser741Thr) and c.2441 T > A (p.Phe814Tyr). According to the GU-AG rule, the c. $1768+1 \mathrm{G}>\mathrm{C}$ mutation was estimated to be a pathogenic mutation on the basis of a change in the corresponding intron to shearing mode, which is genetically consistent with the pathogenic pattern of $\mathrm{X}$-linked recessive inheritance. c.1415_1416insCGGC (p. Gly472fs) is a novel frameshift mutation identified the AR gene. Studies have shown that a 2-base deletion and frameshift mutation at this site can lead to CAIS [27]. Mutations including c.2024 T > A (p. Leu675Gln), c.2351A > G (p. Gln784Arg), c.1684A > T (p. Ile562Phe), c.1768 + 1G > $\mathrm{C}$ and c.1415_1416insCGGC (p. Gly472fs) cause a complete female phenotype, while the c.2441 T > A (p. Phe814Tyr), and c.2221 T > A (p. Ser741Thr) mutations lead to PAIS. The 9 novel AR mutations identified in our study cause different types of AIS. These findings will provide deeper insight into AIS and contribute to its clinical assessment.

\section{Conclusions}

Abnormalities in the AR gene can cause AIS, with phenotypes ranging from CAIS with a complete female phenotype to PAIS with minor degrees of undervirilisation or infertility. In this research, cryptorchidism showed a higher incidence in CAIS than PAIS patients. We demonstrated that AIS patients could not be distinguished solely by their hormone levels of E2, INHB, SHBG, basal LH, basal T, or basal DHT, the T/DHT ratio, T after HCG stimulation or DHT after HCG stimulation. However, CAIS patients exhibited higher hormone levels of basal FSH, peak FSH, and peak LH and lower AMH levels than PAIS patients. We identified 21 reported pathogenic mutations and 9 novel mutations of AR genes that could result in different AIS symptoms. These findings provide deeper insight into AIS diagnosis and will contribute to its clinical assessment.

\section{Abbreviations}

AR: Androgen receptor; AIS: Androgen insensitivity syndrome;

CAIS: Complete androgen insensitivity syndrome; PAIS: Partial androgen insensitivity syndrome; DSD: Disorders of sex development; INHB: Inhibin B; SHBG: Sex hormone-binding globulin; LH: Luteinizing hormone; FSH: Folliclestimulating hormone; T: Testosterone; DHT: Dihydrotestosterone;

E2: Oestradiol; HCG: Human chorionic gonadotropin; AMH: Anti-Mullerian hormone; GnRH: Gonadotropin-releasing hormone; LBD: Ligand-binding domain; NTD: N-terminal domain; DBD: DNA-binding domain

\section{Acknowledgements}

We are grateful to Yongcheng Yang for research platform support and critical comments on the experiments.

\section{Authors' contributions}

Liu Q designed the experiments and analysed the data. Li P contributed reagents/materials/analysis tools. Yin $X$ helped with the data analysis and presentation. All authors read and approved the final manuscript.

\section{Funding}

This work was supported by the National Natural Science Foundation of China (81871131), the Key Subject Program of the Shanghai Municipal Commission of Health and Family Planning (2016ZB0102), the Yangtze River Delta Project of the Shanghai Science and Technology Commission (13495810300) and Medical Professionals Cross Research Fund of Shanghai Jiaotong University (YG2015MS39).

\section{Availability of data and materials}

All data generated or analysed during this study are included in this published article. The datasets used and/or analysed during the current study are available from the corresponding author upon reasonable request.

\section{Ethics approval and consent to participate}

The research was performed in accordance with the principles of the Declaration of Helsinki. The study was approved by the ethics committee of Shanghai Children's Hospital Affiliated with Shanghai Jiao Tong University (2014R005-F01, Shanghai, China). The patients consented to participate in this study.

\section{Consent for publication}

The authors and participants agree to publication.

\section{Competing interests}

The authors declare that they have no competitive interests.

Received: 20 September 2019 Accepted: 16 April 2020

Published online: 28 April 2020

\section{References}

1. Melo KF, Mendonca BB, Billerbeck AE, Costa EM, Latronico AC, Arnhold IJ. Androgen insensitivity syndrome: clinical, hormonal and molecular analysis of 33 cases. Arq Bras Endocrinol Metabol. 2005;49(1):87-97.

2. Hughes IA, Davies JD, Bunch TI, Pasterski V, Mastroyannopoulou K, MacDougall J. Androgen insensitivity syndrome. Lancet (London, England). 2012;380(9851):1419-28.

3. Eisermann $K$, Wang $D$, Jing $Y$, Pascal LE, Wang Z. Androgen receptor gene mutation, rearrangement, polymorphism. Transl Androl Urol. 2013; 2(3):137-47.

4. Ahmed SF, Cheng A, Dovey L, Hawkins JR, Martin H, Rowland J, et al. Phenotypic features, androgen receptor binding, and mutational analysis in 278 clinical cases reported as androgen insensitivity syndrome. J Clin Endocrinol Metab. 2000;85(2):658-65.

5. Prader A. Genital findings in the female pseudo-hermaphroditism of the congenital adrenogenital syndrome; morphology, frequency, development and heredity of the different genital forms. Helv Paediatr Acta. 1954;9(3): 231-48.

6. Miller SA, Dykes DD, Polesky HF. A simple salting out procedure for extracting DNA from human nucleated cells. Nucleic Acids Res. 1988;16(3): 1215.

7. Verhoeven G, Swinnen JV. Indirect mechanisms and cascades of androgen action. Mol Cell Endocrinol. 1999;151(1-2):205-12.

8. Petroli RJ, Hiort O, Struve D, Gesing JK, Soardi FC, Spinola-Castro AM, et al. Functional impact of novel androgen receptor mutations on the clinical manifestation of androgen insensitivity syndrome. Sex Dev. 2017;11(5-6): 238-47.

9. Chang C, Lee SO, Wang RS, Yeh S, Chang TM. Androgen receptor (AR) physiological roles in male and female reproductive systems: lessons learned from AR-knockout mice lacking AR in selective cells. Biol Reprod. 2013;89(1):21.

10. Hughes IA, Deeb A. Androgen resistance. Best Pract Res Clin Endocrinol Metab. 2006;20(4):577-98. 
11. Doehnert U, Bertelloni S, Werner R, Dati E, Hiort O. Characteristic features of reproductive hormone profiles in late adolescent and adult females with complete androgen insensitivity syndrome. Sex Dev. 2015;9(2):69-74.

12. Batista RL, Costa EMF, Rodrigues AS, Gomes NL, Faria JA Jr, Nishi MY, et al. Androgen insensitivity syndrome: a review. Arch Endocrinol Metab. 2018; 62(2):227-35.

13. Bouvattier C, Carel JC, Lecointre C, David A, Sultan C, Bertrand AM, et al. Postnatal changes of $T, L H$, and FSH in $46, X Y$ infants with mutations in the AR gene. J Clin Endocrinol Metab. 2002;87(1):29-32.

14. Freire AV, Grinspon RP, Rey RA. Importance of serum testicular protein hormone measurement in the assessment of disorders of sex development. Sex Dev. 2018;12(1-3):30-40.

15. Weintraub A, Eldar-Geva T. Anti-Mullerian hormone (AMH) determinations in the pediatric and adolescent endocrine practice. Pediatr Endocrinol Rev. 2017:14(4):364-70.

16. Canning DA. Re: pre- and postoperative status of gonadotropins (FSH and $\mathrm{LH})$ and inhibin-B in relation to testicular histopathology at Orchiopexy in infant boys with unilateral undescended testes. J Urol. 2016;196(4):1257-8.

17. Grinspon RP, Gottlieb S, Bedecarras P, Rey RA. Anti-Mullerian hormone and testicular function in Prepubertal boys with cryptorchidism. Front Endocrinol (Lausanne). 2018;9:182.

18. Edelsztein NY, Grinspon RP, Schteingart HF, Rey RA. Anti-Mullerian hormone as a marker of steroid and gonadotropin action in the testis of children and adolescents with disorders of the gonadal axis. Int J Pediatr Endocrinol. 2016;2016:20.

19. Hochberg Z, Chayen R, Reiss N, Falik Z, Makler A, Munichor M, et al. Clinical, biochemical, and genetic findings in a large pedigree of male and female patients with 5 alpha-reductase 2 deficiency. J Clin Endocrinol Metab. 1996; 81(8):2821-7.

20. Audi L, Fernandez-Cancio M, Carrascosa A, Andaluz P, Toran N, Piro C, et al. Novel (60\%) and recurrent (40\%) androgen receptor gene mutations in a series of 59 patients with a $46, \mathrm{XY}$ disorder of sex development. J Clin Endocrinol Metab. 2010;95(4):1876-88.

21. Pinsky L, Trifiro M, Kaufman M, Beitel LK, Mhatre A, Kazemi-Esfarjani P, et al. Androgen resistance due to mutation of the androgen receptor. Clin Invest Med. 1992;15(5):456-72.

22. Ono H, Saitsu H, Horikawa R, Nakashima S, Ohkubo Y, Yanagi K, et al. Partial androgen insensitivity syndrome caused by a deep intronic mutation creating an alternative splice acceptor site of the AR gene. Sci Rep. 2018; 8(1):2287.

23. Gottlieb B, Beitel LK, Nadarajah A, Paliouras M, Trifiro M. The androgen receptor gene mutations database: 2012 update. Hum Mutat. 2012;33(5): 887-94.

24. Holterhus PM, Bruggenwirth HT, Hiort O, Kleinkauf-Houcken A, Kruse K, Sinnecker GH, et al. Mosaicism due to a somatic mutation of the androgen receptor gene determines phenotype in androgen insensitivity syndrome. J Clin Endocrinol Metab. 1997;82(11):3584-9.

25. Kohler B, Lumbroso S, Leger J, Audran F, Grau ES, Kurtz F, et al. Androgen insensitivity syndrome: somatic mosaicism of the androgen receptor in seven families and consequences for sex assignment and genetic counseling. J Clin Endocrinol Metab. 2005;90(1):106-11.

26. Batista RL, Rodrigues AS, Machado AZ, Nishi MY, Cunha FS, Silva RB, et al. Partial androgen insensitivity syndrome due to somatic mosaicism of the androgen receptor. J Pediatr Endocrinol Metab. 2018;31(2):223-8.

27. Ferlin A, Vinanzi C, Garolla A, Selice R, Zuccarello D, Cazzadore C, et al. Male infertility and androgen receptor gene mutations: clinical features and identification of seven novel mutations. Clin Endocrinol. 2006;65(5):606-10.

\section{Publisher's Note}

Springer Nature remains neutral with regard to jurisdictional claims in published maps and institutional affiliations.

\section{Ready to submit your research? Choose BMC and benefit from:}

- fast, convenient online submission

- thorough peer review by experienced researchers in your field

- rapid publication on acceptance

- support for research data, including large and complex data types

- gold Open Access which fosters wider collaboration and increased citations

- maximum visibility for your research: over $100 \mathrm{M}$ website views per year

At BMC, research is always in progress.

Learn more biomedcentral.com/submissions 